\title{
Mapping diluents for water-lean solvents: a parametric study
}

\author{
Ricardo R. Wanderley, Hanna K. Knuutila*
}

Department of Chemical Engineering, Norwegian University of Science and Technology (NTNU), NO-7491 Trondheim, Norway

\section{Supporting Information}

The simulation work on water-lean solvents presented in the main manuscript of this publication relies on many parameters concerning previously published data available in literature, as well as a myriad of empirical correlations also available in literature. Sections 1 and 2 of this Supporting Information appendix sources and summarizes this information. Sections 3, 4 and 5 extend and give an in-depth assessment of the parametric analyses regarding mass transfer rates, thermal phenomena and heat of regeneration in water-lean solvents, complementing the discussion presented in the main manuscript.

\footnotetext{
*Correspondence: hanna.k.knuutila@ntnu.no
} 
Section 1 - Physical, thermodynamical and transport parameters for possible diluents

Table S1-1. Some properties of pure diluents at $298.15 \mathrm{~K}$ for evaluation of mass transfer coefficients

\begin{tabular}{llllll}
\hline Name & $\varepsilon$ & $\mathrm{H} / \mathrm{Pa} \cdot \mathrm{m}^{3} \cdot \mathrm{mol}^{-1}$ & $\mathrm{M} / \mathrm{kg} \cdot \mathrm{mol}^{-1}$ & $\rho / \mathrm{kg} \cdot \mathrm{m}^{-3}$ & $\eta / \mathrm{mPa} \cdot \mathrm{s}$ \\
\hline acetone & 27.4 & 380 & 0.0581 & 784 & 0.31 \\
benzaldehyde & 26.8 & 895 & 0.1061 & 1040 & 1.06 \\
n-butanol & 24.1 & 1200 & 0.0741 & 810 & 2.60 \\
2-butanol & 22.5 & 1412 & 0.0741 & 806 & 3.25 \\
t-butanol & 18.0 & 1326 & 0.0741 & 781 & 4.07 \\
cycloheptanone & 20.1 & 754 & 0.1121 & 949 & 2.11 \\
cyclohexanol & 23.6 & 2240 & 0.1002 & 962 & 22.28 \\
cyclohexanone & 23.1 & 656 & 0.0981 & 948 & 2.05 \\
cyclopentanone & 20.6 & 547 & 0.0841 & 950 & 1.18 \\
dimethyl sulfoxide & 54.1 & 783 & 0.0781 & 1100 & 1.97 \\
dimethyl formamide & 44.9 & 487 & 0.0731 & 944 & 0.84 \\
ethanol & 32.0 & 886 & 0.0461 & 789 & 1.07 \\
ethylene chloride & 17.9 & 708 & 0.0990 & 1250 & 0.50 \\
ethylene glycol & 48.6 & 2575 & 0.0621 & 1110 & 17.60 \\
N-formyl morpholine & 24.3 & 691 & 0.1151 & 1145 & 7.67 \\
glycerol & 53.9 & 82286 & 0.0921 & 1260 & 749.34 \\
heptanol & 17.0 & 1143 & 0.1162 & 819 & 5.78 \\
\hline
\end{tabular}




\begin{tabular}{|c|c|c|c|c|c|}
\hline hexanol & 18.4 & 1083 & 0.1022 & 814 & 4.60 \\
\hline isoamyl alcohol & 17.7 & 1363 & 0.0881 & 810 & 3.69 \\
\hline isobutanol & 23.4 & 1351 & 0.0741 & 802 & 3.27 \\
\hline isopropanol & 26.1 & 1185 & 0.0601 & 786 & 2.02 \\
\hline methanol & 39.6 & 685 & 0.0320 & 792 & 0.54 \\
\hline methyl ethyl ketone & 25.1 & 371 & 0.0721 & 805 & 0.40 \\
\hline nitrobenzene & 44.4 & 1031 & 0.1231 & 1200 & 1.89 \\
\hline N-methyl-2-pyrrolidone & 41.2 & 613 & 0.0991 & 1030 & 1.19 \\
\hline pentanol & 21.1 & 1361 & 0.0881 & 814 & 3.51 \\
\hline phenyl acetonitrile & 26.3 & 1216 & 0.1171 & 1020 & 1.76 \\
\hline propanol & 27.6 & 1028 & 0.0601 & 803 & 1.94 \\
\hline propionitrile & 36.4 & 420 & 0.0551 & 792 & 0.41 \\
\hline propylene carbonate & 68.6 & 752 & 0.1021 & 1200 & 2.47 \\
\hline pyridine & 20.1 & 688 & 0.0791 & 982 & 0.90 \\
\hline sulfolane & 52.2 & 1209 & 0.1202 & 1260 & 9.29 \\
\hline water & 78.4 & 2943 & 0.0180 & 997 & 0.88 \\
\hline
\end{tabular}

Table S1-2. Parameters for the calculation of $\mathrm{C}_{\mathrm{P}}$ and $\mathrm{p}^{\text {sat }}$ dependent on temperature for evaluation of temperature bulge and reboiler heat duties

\begin{tabular}{llllllll}
\hline Name & \multicolumn{2}{l}{$\mathrm{C}_{\mathrm{P}} / \mathrm{J} \cdot \mathrm{mol}^{-1} \cdot \mathrm{K}^{-1}$} & \multicolumn{3}{l}{$\mathrm{p}^{\mathrm{sat} / \mathrm{mmHg}}$} \\
& $\mathrm{A}$ & $\mathrm{B}$ & $\mathrm{C}$ & $\mathrm{D}$ & $\mathrm{E}$ & $\mathrm{A}$ & $\mathrm{B}$ \\
\hline acetone & 354.77 & -3.5109 & 0.01873 & $-4.32 \cdot 10^{-5}$ & $3.79 \cdot 10^{-8}$ & 7.3174 & 1315.7
\end{tabular}




\begin{tabular}{|c|c|c|c|c|c|c|c|c|}
\hline benzaldehyde & -4.14 & 2.1721 & -0.01138 & $2.66 \cdot 10^{-5}$ & $-2.15 \cdot 10^{-8}$ & 7.2504 & 1733.8 & 217.93 \\
\hline n-butanol & -368.41 & 5.8164 & -0.02334 & $3.78 \cdot 10^{-5}$ & $-1.53 \cdot 10^{-8}$ & 7.3013 & 1285.0 & 173.25 \\
\hline 2-butanol & 95.04 & 0.5659 & -0.00183 & $2.67 \cdot 10^{-6}$ & & 7.5140 & 1322.1 & 186.51 \\
\hline t-butanol & 33895.81 & -334.2440 & 1.23745 & $-2.03 \cdot 10^{-3}$ & $1.24 \cdot 10^{-6}$ & 7.1380 & 1069.8 & 168.93 \\
\hline cyclohexanol & 9520.38 & -98.0722 & 0.38124 & $-6.50 \cdot 10^{-4}$ & $4.12 \cdot 10^{-7}$ & 7.1928 & 1415.3 & 168.37 \\
\hline cyclohexanone & 55.20 & 0.8669 & -0.00228 & $2.50 \cdot 10^{-6}$ & & 7.6413 & 1894.1 & 243.04 \\
\hline cyclopentanone & 108.86 & 0.3222 & -0.00079 & $1.16 \cdot 10^{-6}$ & & 7.5659 & 1727.9 & 238.15 \\
\hline dimethyl sulfoxide & 27.88 & 0.7863 & -0.00178 & $1.65 \cdot 10^{-6}$ & & 6.6160 & 1807.0 & 212.16 \\
\hline dimethyl formamide & 59.53 & 0.6071 & -0.00162 & $1.86 \cdot 10^{-6}$ & & 7.2413 & 1597.9 & 213.46 \\
\hline ethanol & 238.31 & -2.3806 & 0.01332 & $-3.20 \cdot 10^{-5}$ & $3.15 \cdot 10^{-8}$ & 8.1288 & 1660.9 & 238.13 \\
\hline ethylene chloride & 279.71 & -4.0207 & 0.02963 & $-9.16 \cdot 10^{-5}$ & $1.03 \cdot 10^{-7}$ & 6.9468 & 1064.7 & 246.01 \\
\hline ethylene glycol & -57.24 & 1.4568 & -0.00433 & $7.36 \cdot 10^{-6}$ & $-4.83 \cdot 10^{-9}$ & 9.6960 & 3145.9 & 264.25 \\
\hline glycerol & 170.13 & -1.2561 & 0.00965 & $-2.05 \cdot 10^{-5}$ & $1.37 \cdot 10^{-8}$ & 6.9366 & 1429.6 & 62.49 \\
\hline heptanol & 7270.49 & -86.5244 & 0.38466 & $-7.32 \cdot 10^{-4}$ & $5.09 \cdot 10^{-7}$ & 7.2488 & 1496.6 & 167.77 \\
\hline hexanol & 3737.83 & -42.8835 & 0.18513 & $-3.38 \cdot 10^{-4}$ & $2.25 \cdot 10^{-7}$ & 7.3664 & 1544.6 & 187.50 \\
\hline isoamyl alcohol & -103.06 & 4.7476 & -0.03263 & $9.64 \cdot 10^{-5}$ & $-9.56 \cdot 10^{-8}$ & 7.0671 & 1174.1 & 149.61 \\
\hline isobutanol & -368.29 & 9.0442 & -0.06030 & $1.72 \cdot 10^{-4}$ & $-1.69 \cdot 10^{-7}$ & 7.1612 & 1164.4 & 164.39 \\
\hline isopropanol & 873.15 & -10.0593 & 0.04574 & $-8.38 \cdot 10^{-5}$ & $5.56 \cdot 10^{-8}$ & 7.8252 & 1482.1 & 217.41 \\
\hline methanol & 428.90 & -5.3316 & 0.02846 & $-6.49 \cdot 10^{-5}$ & $5.49 \cdot 10^{-8}$ & 8.0840 & 1580.5 & 239.10 \\
\hline methyl ethyl ketone & -441.72 & 8.9759 & -0.05040 & $1.23 \cdot 10^{-4}$ & $-1.09 \cdot 10^{-7}$ & 7.1913 & 1323.1 & 227.09 \\
\hline monoethanolamine & 2684.80 & -28.4154 & 0.11745 & $-2.11 \cdot 10^{-4}$ & $1.41 \cdot 10^{-7}$ & 7.4424 & 1561.0 & 171.20 \\
\hline
\end{tabular}




\begin{tabular}{lllllllll}
\hline nitrobenzene & 525.49 & -3.7484 & 0.01408 & $-2.18 \cdot 10^{-5}$ & $1.27 \cdot 10^{-8}$ & 7.5363 & 2017.8 & 222.58 \\
NMP & 362.07 & 0.2770 & -0.00060 & $7.90 \cdot 10^{-7}$ & & 6.8409 & 1367.0 & 143.14 \\
pentanol & -546.33 & 11.8545 & -0.07300 & $1.93 \cdot 10^{-4}$ & $-1.78 \cdot 10^{-7}$ & 7.2154 & 1333.5 & 169.78 \\
propanol & 407.92 & -4.6264 & 0.02516 & $-5.77 \cdot 10^{-5}$ & $5.20 \cdot 10^{-8}$ & 7.7766 & 1518.8 & 213.08 \\
propionitrile & -123.32 & 3.4345 & -0.01879 & $4.51 \cdot 10^{-5}$ & $-3.89 \cdot 10^{-8}$ & 7.0634 & 1275.0 & 208.00 \\
propylene carbonate & 101.58 & 0.2256 & & & & 8.5528 & 3408.3 & 359.19 \\
pyridine & 240.72 & -1.5347 & 0.00674 & $-1.15 \cdot 10^{-5}$ & $7.42 \cdot 10^{-9}$ & 7.1837 & 1462.7 & 224.60 \\
sulfolane & 155.05 & 0.2706 & -0.00048 & $5.72 \cdot 10^{-7}$ & & 7.4719 & 2234.2 & 201.79 \\
water & -22.42 & 0.8770 & -0.00257 & $2.48 \cdot 10^{-6}$ & & 8.0557 & 1723.6 & 233.08 \\
\hline
\end{tabular}

Table S1-3. Parameters for the calculation of $\lambda$ and $\eta$ dependent on temperature for evaluation of reboiler heat duties.

\begin{tabular}{llllllll}
\hline Name & \multicolumn{2}{l}{$\lambda / \mathrm{W} \cdot \mathrm{m}^{-1} \cdot \mathrm{K}^{-1}$} & & \multicolumn{2}{l}{$\eta \mathrm{mPa} \cdot \mathrm{s}$} & & $\mathrm{D}$ \\
& $\mathrm{A}$ & $\mathrm{B}$ & $\mathrm{C}$ & $\mathrm{A}$ & $\mathrm{B}$ & $\mathrm{C}$ & $-2.04 \cdot 10^{-5}$ \\
\hline acetone & -1.3857 & 0.7643 & 508.2 & -7.2126 & 903.05 & 0.01839 & $-5.91 \cdot 10^{-6}$ \\
benzaldehyde & -2.4889 & 1.9557 & 695.0 & -4.2147 & 823.40 & 0.00672 & $-5.51 \cdot 10^{-6}$ \\
n-butanol & -1.3120 & 0.6190 & 562.9 & -5.3970 & 1325.60 & 0.00622 & $-3.09 \cdot 10^{-5}$ \\
2-butanol & -1.4633 & 0.7473 & 536.0 & -20.6736 & 3549.30 & 0.04035 & $-6.35 \cdot 10^{-5}$ \\
t-butanol & -1.2018 & 0.3521 & 506.2 & -35.2655 & 5473.70 & 0.07774 & $1.02 \cdot 10^{-7}$ \\
cyclohexanol & -1.3475 & 0.5719 & 625.2 & -5.3792 & 1879.30 & 0.00170 & $-3.75 \cdot 10^{-6}$ \\
cyclohexanone & -1.7647 & 1.0954 & 629.2 & -3.5761 & 931.18 & 0.00369 & $-7.93 \cdot 10^{-5}$ \\
cyclopentanone & -1.5890 & 0.9910 & 626.0 & -53.1880 & 8165.00 & 0.11041 & - \\
\hline
\end{tabular}




\begin{tabular}{|c|c|c|c|c|c|c|c|}
\hline dimethyl sulfoxide & -2.3306 & 1.7746 & 726.0 & -3.6341 & 854.87 & 0.00487 & $-4.41 \cdot 10^{-6}$ \\
\hline dimethyl formamide & -1.4326 & 0.8321 & 647.0 & -5.3292 & 895.47 & 0.01056 & $-1.01 \cdot 10^{-5}$ \\
\hline ethanol & -1.3172 & 0.6987 & 516.3 & -3.1970 & 740.84 & 0.00463 & $-7.17 \cdot 10^{-6}$ \\
\hline ethylene chloride & -2.0001 & 1.4496 & 460.4 & -4.4279 & 518.91 & 0.01204 & $-1.66 \cdot 10^{-5}$ \\
\hline ethylene glycol & -0.5918 & 0.0000 & 645.0 & -16.5536 & 3161.60 & 0.03072 & $-2.21 \cdot 10^{-5}$ \\
\hline glycerol & -0.3550 & -0.2097 & 723.0 & -18.2152 & 4230.50 & 0.02871 & $-1.86 \cdot 10^{-5}$ \\
\hline heptanol & -1.5652 & 0.9223 & 631.9 & -13.9237 & 2629.60 & 0.02533 & $-1.90 \cdot 10^{-5}$ \\
\hline hexanol & -1.3521 & 0.6421 & 611.4 & -9.7166 & 2006.00 & 0.01591 & $-1.23 \cdot 10^{-5}$ \\
\hline isoamyl alcohol & -0.8268 & 0.0000 & 579.5 & -7.9943 & 1769.10 & 0.01148 & $-8.93 \cdot 10^{-6}$ \\
\hline isobutanol & -1.3936 & 0.6487 & 547.7 & -11.9687 & 2177.00 & 0.02377 & $-2.14 \cdot 10^{-5}$ \\
\hline isopropanol & -1.3721 & 0.6580 & 508.3 & -7.4681 & 1546.37 & 0.01213 & $-1.16 \cdot 10^{-5}$ \\
\hline methanol & -1.1793 & 0.6191 & 512.6 & -5.0979 & 825.29 & 0.01066 & $-1.26 \cdot 10^{-5}$ \\
\hline methyl ethyl ketone & -1.4647 & 0.7938 & 535.5 & -0.8761 & 292.57 & -0.00198 & $9.44 \cdot 10^{-7}$ \\
\hline monoethanolamine & -1.3743 & 1.0185 & 638.0 & -13.1818 & 2859.60 & 0.02083 & $-1.42 \cdot 10^{-5}$ \\
\hline nitrobenzene & -1.3942 & 0.6571 & 719.0 & -7.7710 & 1401.90 & 0.01465 & $-1.15 \cdot 10^{-5}$ \\
\hline NMP & -1.1284 & 0.4817 & 724.0 & -4.6506 & 929.42 & 0.00738 & $-6.10 \cdot 10^{-6}$ \\
\hline pentanol & -1.2628 & 0.5481 & 586.2 & -6.9286 & 1560.90 & 0.00996 & $-8.35 \cdot 10^{-6}$ \\
\hline propanol & -1.2131 & 0.5097 & 536.7 & -3.7702 & 991.51 & 0.00408 & $-5.46 \cdot 10^{-6}$ \\
\hline propionitrile & -1.5733 & 0.9918 & 564.4 & -5.6142 & 802.33 & 0.01245 & $-1.33 \cdot 10^{-5}$ \\
\hline propylene carbonate & & & & 6.1452 & & -0.02984 & $3.54 \cdot 10^{-51}$ \\
\hline pyridine & -1.2083 & 0.5146 & 620.0 & -6.8100 & 1149.60 & 0.01323 & $-1.17 \cdot 10^{-5}$ \\
\hline
\end{tabular}




\begin{tabular}{llllllll}
\hline sulfolane & -1.4179 & 0.8122 & 849.0 & -2.6246 & 908.25 & 0.00274 & $-2.74 \cdot 10^{-6}$ \\
water* & & & & -11.6225 & 1948.96 & 0.02164 & $-1.60 \cdot 10^{-5}$ \\
\hline
\end{tabular}

* For water, the expression for thermal conductivity is slightly different than that shown in this Section. One is advised to refer to Yaws ${ }^{2}$ for the right expression and parameters. 
Table S1-4. Parameters for the calculation of $\rho$ dependent on temperature for evaluation of reboiler heat duties.

\begin{tabular}{|c|c|c|c|c|}
\hline \multirow[t]{2}{*}{ Name } & \multicolumn{4}{|c|}{$\rho / \mathrm{g} \cdot \mathrm{cm}^{-3}$} \\
\hline & A & $\mathrm{B}$ & $\mathrm{C}$ & $\mathrm{n}$ \\
\hline acetone & 0.2779 & 0.2582 & 508.20 & 0.2990 \\
\hline benzaldehyde & 0.3275 & 0.2578 & 695.00 & 0.2850 \\
\hline n-butanol & 0.2700 & 0.2681 & 562.93 & 0.2457 \\
\hline 2-butanol & 0.2766 & 0.2671 & 536.01 & 0.2604 \\
\hline t-butanol & 0.2695 & 0.2565 & 506.20 & 0.2737 \\
\hline cyclohexanol & 0.3111 & 0.2577 & 625.15 & 0.2857 \\
\hline cyclohexanone & 0.2889 & 0.2417 & 629.15 & 0.2857 \\
\hline cyclopentanone & 0.3260 & 0.2716 & 626.00 & 0.3133 \\
\hline dimethyl sulfoxide & 0.3442 & 0.2536 & 726.00 & 0.3220 \\
\hline dimethyl formamide & 0.2738 & 0.2301 & 647.00 & 0.2763 \\
\hline ethanol & 0.2760 & 0.2767 & 516.25 & 0.2367 \\
\hline ethylene chloride & 0.3226 & 0.2748 & 460.35 & 0.2314 \\
\hline ethylene glycol & 0.3250 & 0.2550 & 645.00 & 0.1720 \\
\hline glycerol & 0.3488 & 0.2487 & 723.00 & 0.1541 \\
\hline heptanol & 0.2670 & 0.2630 & 631.90 & 0.2730 \\
\hline hexanol & 0.2680 & 0.2672 & 611.35 & 0.2540 \\
\hline isoamyl alcohol & 0.2696 & 0.2578 & 579.45 & 0.2857 \\
\hline isobutanol & 0.2725 & 0.2752 & 547.73 & 0.2344 \\
\hline isopropanol & 0.2730 & 0.2709 & 508.31 & 0.2430 \\
\hline methanol & 0.2720 & 0.2721 & 512.58 & 0.2331 \\
\hline methyl ethyl ketone & 0.2701 & 0.2545 & 535.50 & 0.2857 \\
\hline monoethanolamine & 0.2715 & 0.2240 & 638.00 & 0.2015 \\
\hline nitrobenzene & 0.3528 & 0.2404 & 719.00 & 0.2857 \\
\hline N-methyl-2-pyrrolidone & 0.3137 & 0.2544 & 724.00 & 0.2736 \\
\hline pentanol & 0.2704 & 0.2688 & 586.15 & 0.2506 \\
\hline propanol & 0.2750 & 0.2698 & 536.71 & 0.2494 \\
\hline propionitrile & 0.2405 & 0.2351 & 564.40 & 0.2804 \\
\hline pyridine & 0.3114 & 0.2470 & 619.95 & 0.3045 \\
\hline sulfolane & 0.4006 & 0.2690 & 849.00 & 0.3040 \\
\hline
\end{tabular}




\begin{tabular}{lllll}
\hline water & 0.3250 & 0.2700 & 647.13 & 0.2300
\end{tabular}

The expression for the calculation of the heat capacity is given below, where the temperature should be input in $\mathrm{K}$ and the resulting $\mathrm{C}_{\mathrm{P}}$ comes in $\mathrm{J} \cdot \mathrm{mol}^{-1} \cdot \mathrm{K}^{-1}$.

$$
C_{P}=A+B \cdot T+C \cdot T^{2}+D \cdot T^{3}+E \cdot T^{4}
$$

The expression for the calculation of the saturation pressure is given below, where the temperature should be input in ${ }^{\circ} \mathrm{C}$ and the resulting $\mathrm{p}^{\text {sat }}$ comes in $\mathrm{mmHg}$.

$$
\log _{10}\left(p^{s a t}\right)=A-\frac{B}{T+C}
$$

The expression for the calculation of the heat conductivity is given below, where the temperature should be input in $\mathrm{K}$ and the resulting $\lambda$ comes in $\mathrm{W} \cdot \mathrm{m}^{-1} \cdot \mathrm{K}^{-1}$.

$$
\log _{10}(\lambda)=A+B \cdot\left(1-\frac{T}{C}\right)^{\frac{2}{7}}
$$

The expression for the calculation of the viscosity is given below, where the temperature should be input in $\mathrm{K}$ and the resulting $\eta$ comes in $\mathrm{mPa} \cdot \mathrm{s}$.

$$
\log _{10}(\eta)=A+\frac{B}{T}+C \cdot T+D \cdot T^{2}
$$

The expression for the calculation of the density is given below, where the temperature should be input in $\mathrm{K}$ and the resulting $\rho$ comes in $\mathrm{g} \cdot \mathrm{cm}^{-3}$.

$$
\rho=A \cdot B^{-\left(1-\frac{T}{C}\right)^{n}}
$$

The Henry's coefficients for $\mathrm{CO}_{2}$ in Table S1-1 come from Hansen ${ }^{3}$, while the dielectric permittivities come from Rumble et al. ${ }^{4}$. All densities and viscosities in Table S1-1 were evaluated by the expressions shown in this Section, with the exception of those for N-formyl morpholine, which were obtained elsewhere ${ }^{5}$ Most of the parameters shown in Table S1-2, Table S1-3 and Table S1-4 were obtained in the series of books published by Yaws ${ }^{6-9}$. For propylene carbonate, all of the parameters had to be regressed from data available in the literature $^{1,10-13}$. For dimethyl sulfoxide, the coefficients of the Antoine equation were regressed from Jakli and van Hook ${ }^{14}$. 
The heat of vaporization of a substance can be estimated by the Clausius-Clapeyron equation with the assumption of ideal gas in the vapor phase. In the present formulation, the temperature is input in $\mathrm{K}$ and the gas constant is $8.314 \mathrm{~J} \cdot \mathrm{mol}^{-1} \cdot \mathrm{K}^{-1}$, and the resulting $\mathrm{L}$ comes in $\mathrm{J} \cdot \mathrm{mol}^{-1}$. The parameters $\mathrm{B}$ and $\mathrm{C}$ are the same from the Antoine equation for calculating $\mathrm{p}^{\text {sat }}$.

$$
L=\frac{R \cdot B \cdot \ln (10)}{(T+C-273.15)^{2}} \cdot T^{2}
$$

\section{Section 2 - Mixing rules}

Most of the mixing rules shown in this chapter were obtained in The Properties of Gases and Liquids $^{15}$ and are valid for ideal mixtures. The ones obtained elsewhere will be addressed individually.

The viscosity of ideal mixtures is a modified Arrhenius rule ${ }^{16,17}$ shown below. In that expression, $\mathrm{w}_{\mathrm{i}}$ is the mass fraction of each component $\mathrm{i}$ in the mixture and $\mathrm{NC}$ is the total number of components.

$$
\ln (\eta)=\sum_{i=1}^{N C} w_{i} \cdot \ln \left(\eta_{i}\right)
$$

The combined heat capacity of either gases or liquids is simply a molar average, with $\mathrm{x}_{\mathrm{i}}$ being the molar fraction of each individual component. This time, this relationship is not mediated by logarithms. It is important to notice that each individual heat capacity must be input in $\mathrm{J} \cdot \mathrm{mol}^{-1} \cdot \mathrm{K}^{-1}$ in the expression below.

$$
C_{P}=\sum_{i=1}^{N C} x_{i} \cdot C_{P i}
$$

The viscosity of an ideal mixture is calculated by relying on the assumption that each molar volume shall be the same as that of the pure component. Therefore, the resulting expression is given below. The molar mass of each component is denoted by $\mathrm{M}_{\mathrm{i}}$.

$$
\rho=\frac{\sum_{i=1}^{N C}{ }^{x_{i}} \cdot M_{i}}{\sum_{i=1}^{N C} \frac{x_{i} \cdot M_{i}}{\rho_{i}}}
$$


The thermal conductivity of binary liquid mixtures was calculated by the Filippov equation shown below. Each component is chosen so that $\lambda_{2}>\lambda_{1}$, and the weights $\mathrm{w}_{1}$ and $\mathrm{w}_{2}$ are the mass fractions of components 1 and 2 respectively.

$$
\lambda=w_{1} \cdot \lambda_{1}+w_{2} \cdot \lambda_{2}-0.72 \cdot w_{1} \cdot w_{2} \cdot\left(\lambda_{2}-\lambda_{1}\right)
$$

Following our previous work ${ }^{18}$, a mixing rule for dielectric permittivities was obtained in Reynolds and Hough ${ }^{19}$. In the expression below, valid for binary mixtures only, the parameter $\delta_{1}$ is the volume fraction of component 1 in the mixture.

$$
\frac{\varepsilon-\varepsilon_{2}}{\varepsilon+2 \cdot \varepsilon_{2}}=\delta_{1} \cdot \frac{\varepsilon_{1}-\varepsilon_{2}}{\varepsilon_{1}+2 \cdot \varepsilon_{2}}
$$

Finally, the mixing rule for the Henry's coefficient is the Krichevsky equation ${ }^{20}$ shown below, which looks quite similar to the Arrhenius law for viscosity of mixtures.

$$
\ln H_{A}=\sum_{i=1}^{N C} x_{i} \cdot \ln \left(H_{A, i}\right)
$$

\section{Section 3 - Explicit parametric analysis for mass transfer coefficients}

This Section 3 will take the six parameters used for mass transfer modelling - the kinetic parameters $\mathrm{k}_{2}$ and $\mathrm{k}_{\mathrm{b}} / \mathrm{k}_{-1}$, the transport parameters $\mathrm{D}_{\mathrm{A}}$ and $\mathrm{D}_{\mathrm{B}}$, the thermodynamic parameter $\mathrm{H}_{\mathrm{A}}$ and the electrochemical parameter $\varepsilon$ - and look at how they affect $\mathrm{k}_{\mathrm{g}}$ * averaged for a column operating with a $\mathrm{CO}_{2}$ gas stream with $\mathrm{p}_{\mathrm{A}}=0-1000 \mathrm{~Pa}, \Delta \mathrm{p}_{\mathrm{A}}=100 \mathrm{~Pa}$ and $\tau=0.05 \mathrm{~s}$.

The solvent consists in $30 \% \mathrm{wt}$. MEA with different diluents. The relevant parameters for aqueous $30 \%$ wt. MEA were obtained in Sada et al. ${ }^{21}$ and Snijder et al..$^{22}$, while the VLE behavior was fitted to data published by Aronu et al. ${ }^{23}$ through the soft model ${ }^{24}$. The diffusivity $\mathrm{D}_{\mathrm{A}}$ was evaluated by the Wilke-Chang correlation, and $\mathrm{H}_{\mathrm{A}}$ was estimated by a mixing rule with the individual parameters for water and MEA, both obtained in literature ${ }^{3}$. The dielectric permittivity of water, as well as all dielectric permittivities shown in this work, were also drawn from literature ${ }^{4}$. For aqueous $30 \% \mathrm{wt}$. MEA, $\mathrm{k}_{2}=7.740 \mathrm{~m}^{3} \cdot \mathrm{mol}^{-1} \cdot \mathrm{s}^{-1}, \mathrm{k}_{\mathrm{b}} / \mathrm{k}_{-1}=\infty$ (for simulation purposes $\mathrm{k}_{\mathrm{b}} / \mathrm{k}_{-1}=10 \mathrm{~m}^{3} \cdot \mathrm{mol}^{-1}$, a high enough number), $\mathrm{D}_{\mathrm{A}}=2.06 \cdot 10^{-9} \mathrm{~m}^{2} \cdot \mathrm{s}^{-1}, \mathrm{D}_{\mathrm{B}}=5.11 \cdot 10^{-10}$ $\mathrm{m}^{2} \cdot \mathrm{s}^{-1}, \mathrm{H}_{\mathrm{A}}=3168 \mathrm{~Pa} \cdot \mathrm{m}^{3} \cdot \mathrm{mol}^{-1}$ and $\varepsilon=78.4$.

In each one of the following computational experiments, one single parameter is allowed to vary while all of the others are fixed to the base values for aqueous $30 \% \mathrm{wt}$. MEA, so that the 
unitary effects of individual components can be better apprehended. The effect is then shown in terms of $\mathrm{k}_{\mathrm{g}}{ }^{*}$ averaged. Both scenarios CASE A (with VLE shift due to electrostatic phenomena) and CASE B (without VLE shift) will be shown individually. For a better discussion on what CASE A and CASE B entail, refer to Section Error! Reference source not found.
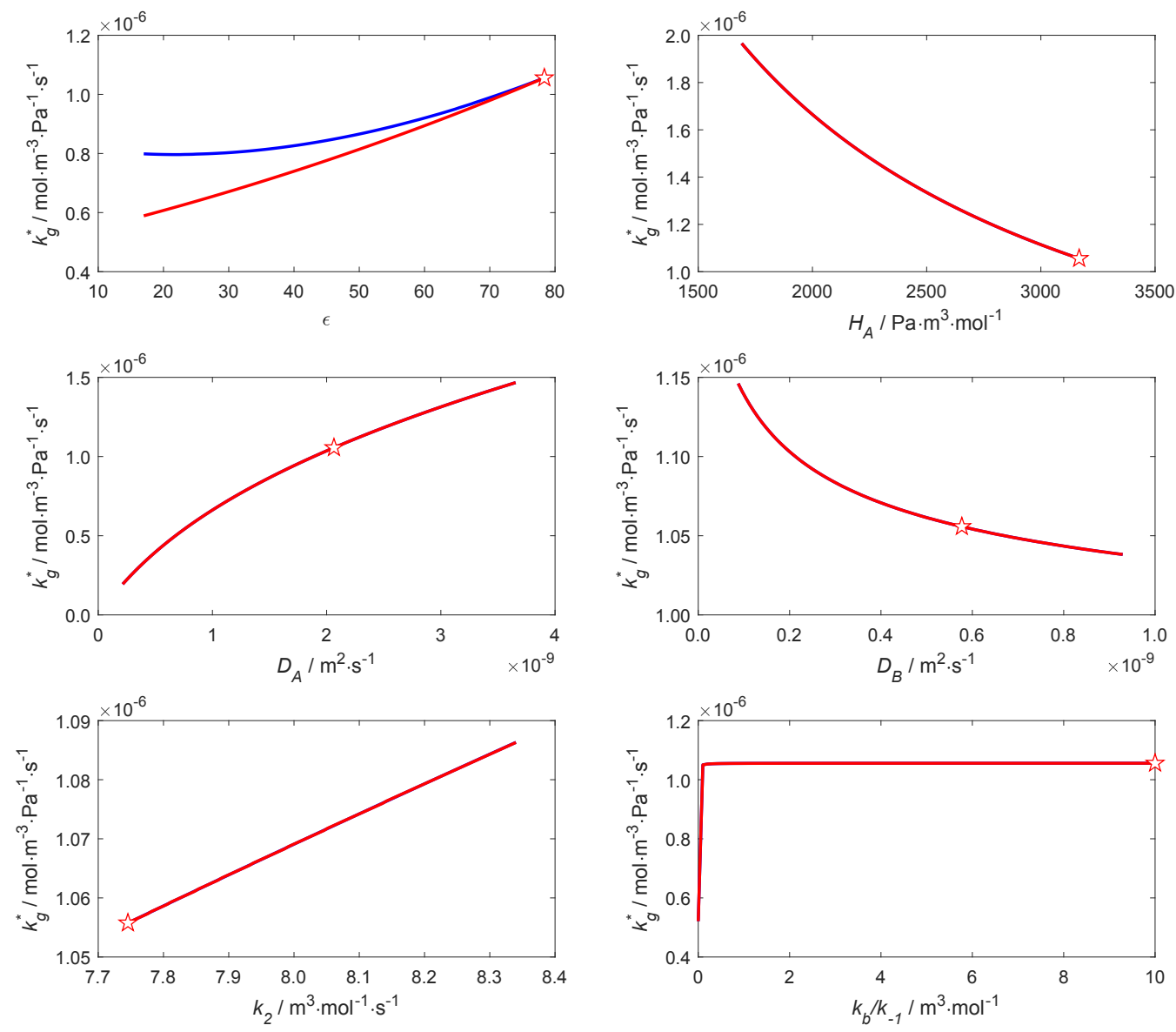

Figure S3-1. Analyses on the effect of different explicit parameters on the mass transfer performance of solvents based on aqueous $30 \% \mathrm{wt}$. MEA $\left(\mathrm{p}_{\mathrm{A}}=0-1000 \mathrm{~Pa}, \Delta \mathrm{p}_{\mathrm{A}}=100 \mathrm{~Pa}, \tau\right.$ $=0.05 \mathrm{~s}$ ); the blue lines refer to CASE A whereas the red lines refer to CASE B. The stars represent values obtained for the base case with aqueous MEA.

As it can be seen on Figure S3-1, there is mostly an overlap among the red and blue lines. This is because the effects of VLE shift do not apply at all if $\varepsilon$ is fixed at its value for water, meaning that five out of the six plots in Figure S3-1 show rigorously the same two curves. To make this study more interesting, the same procedure has been replicated with the base-case of NMP + $30 \%$ wt. MEA being chosen instead of aqueous MEA. The parameters for NMP $+30 \% \mathrm{wt}$. 
MEA were evaluated by the procedures described in the previous sections. Those are $\varepsilon=41.2$, $\mathrm{H}_{\mathrm{A}}=1829 \mathrm{~Pa} \cdot \mathrm{m}^{3} \cdot \mathrm{mol}^{-1}, \mathrm{D}_{\mathrm{A}}=2.15 \cdot 10^{-9} \mathrm{~m}^{2} \cdot \mathrm{s}^{-1}, \mathrm{D}_{\mathrm{B}}=5.96 \cdot 10^{-10} \mathrm{~m}^{2} \cdot \mathrm{s}^{-1}, \mathrm{k}_{2}=8.285 \mathrm{~m}^{3} \cdot \mathrm{mol}^{-1} \cdot \mathrm{s}^{-1}$ and $\mathrm{k}_{\mathrm{b}} / \mathrm{k}_{-1}=3.18 \cdot 10^{-3} \mathrm{~m}^{3} \cdot \mathrm{mol}^{-1}$. The results are shown in Figure S3-2.
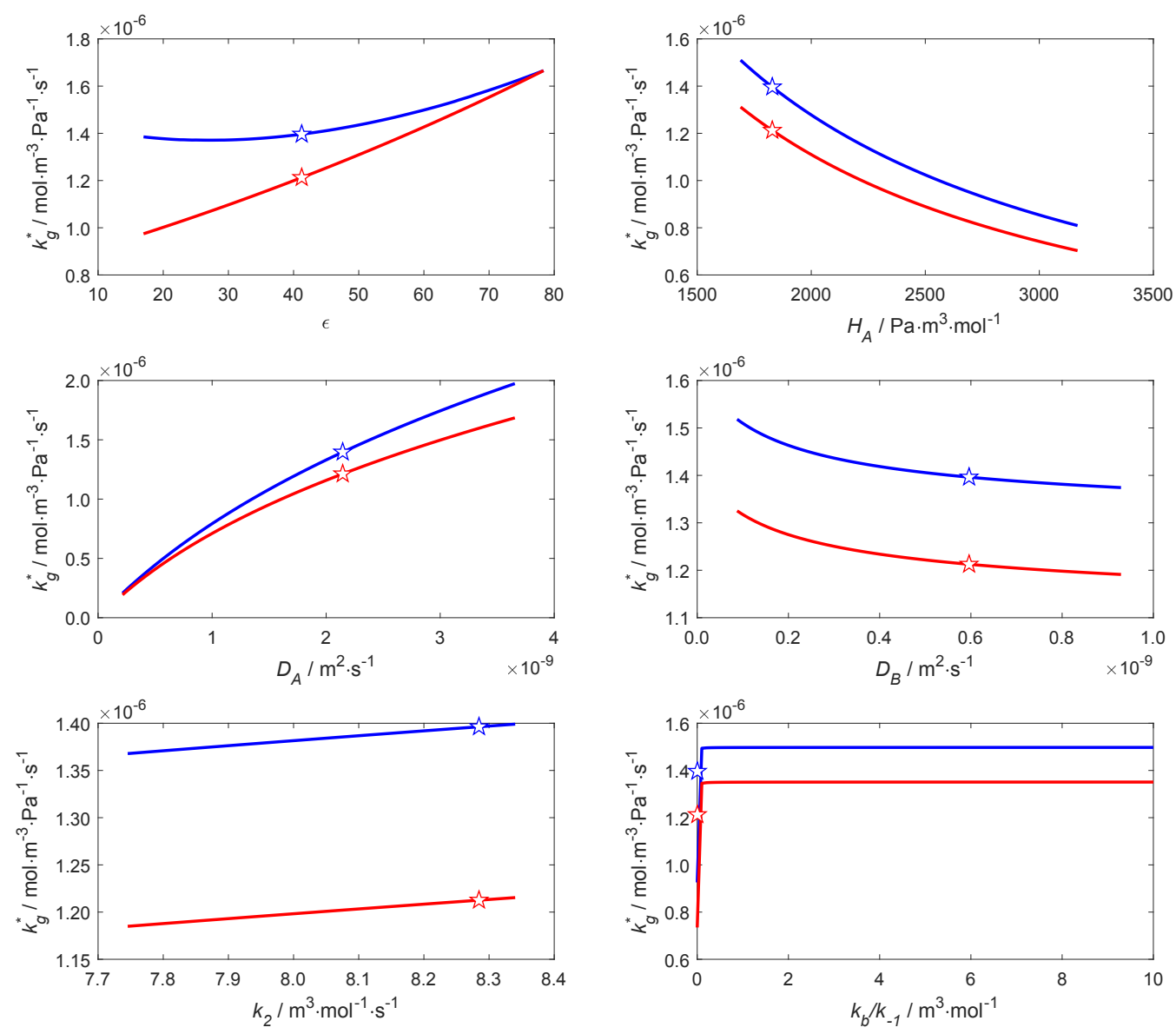

Figure S3-2. Analyses on the effect of different explicit parameters on the mass transfer performance of solvents based on NMP $+30 \%$ wt. MEA $\left(\mathrm{p}_{\mathrm{A}}=0-1000 \mathrm{~Pa}, \Delta \mathrm{p}_{\mathrm{A}}=100 \mathrm{~Pa}, \tau=\right.$ $0.05 \mathrm{~s}$ ); the blue lines refer to CASE A whereas the red lines refer to CASE B. The stars represent values obtained for the base case with NMP + MEA.

In general, the trends observed both in Figure S3-1 and in Figure S3-2 are very straightforward. Higher values of $\varepsilon$ typically increase $\mathrm{k}_{\mathrm{g}}{ }^{*}$ averaged, as the increase in viscosity (and the decrease in diffusivities) is less steep in solvents where electrolytes can be more easily stabilized. However, there is a clear difference between CASE A and CASE B. In the former, the VLEshift implies that the solvent will be less loaded for a fixed value of $\mathrm{p}_{\mathrm{A}}$ if its $\varepsilon$ is lower than that of water. Since this study imposes a range of $\mathrm{CO}_{2}$ partial pressures in the absorber, solvents with lower $\varepsilon$ end up less loaded at the bottom of the column, smoothing out the impacts of 
viscosity change with loading. This explains why the blue lines in the $\mathrm{k}_{\mathrm{g}}{ }^{*}$ vs. $\varepsilon$ plots in Figure S3-1 and in Figure S3-2 are not only less steep than the red lines but also have inflections in their middle range.

Besides that, there is little difference between the parametric analyses with or without VLEshift. Increases in $\mathrm{H}_{\mathrm{A}}$ produce diminishing mass transfer coefficients $\mathrm{k}_{\mathrm{g}}{ }^{*}$, while increases in $D_{A}$ and $k_{2}$ will enhance $k_{g}{ }^{*}$. Both of these results are as expected.

A surprising result of this analysis is that higher amine diffusivities $D_{B}$ seem to decrease $\mathrm{k}_{\mathrm{g}}{ }^{*}$ both in Figure S3-1 and in Figure S3-2, for CASE A and CASE B alike. This goes against intuition, and also against what has been reported by $\mathrm{Hoff}^{25}$ in his modelling results. We have attempted to look more in depth into the reasons for this phenomenon in our simulations. As it can be seen in Figure S3-3, it seems like increases in $\mathrm{D}_{\mathrm{B}}$ enhance the penetration depth of $\mathrm{CO}_{2}$ but drive all concentrations in the profile away from the equilibrium concentrations. This happens because the surface renewal time is very limited, and one might hypothesize that at different values of $\tau$ the behavior observed would be quite different (although we have run the same analysis with $\tau=0.20$ and ended up getting similar results to those shown in Figure S33 , only with larger penetration depths). 


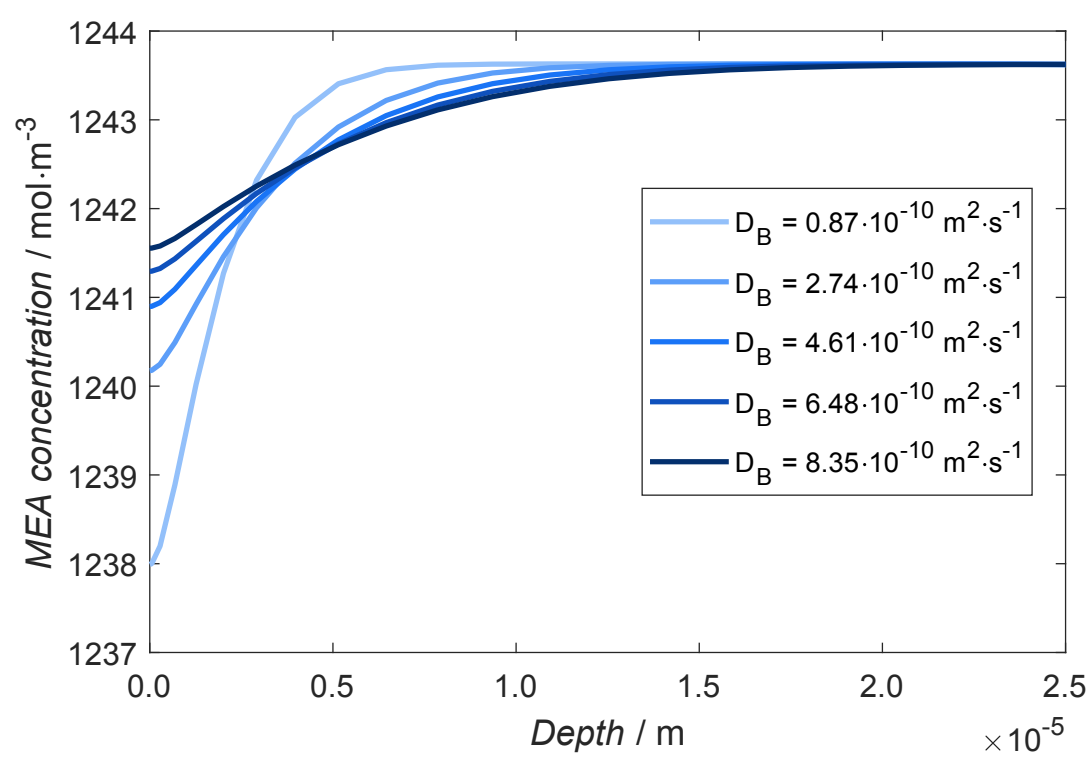

Figure S3-3. Penetration profiles in terms of unreacted MEA concentration for variations in

$\mathrm{D}_{\mathrm{B}}$ while fixing all other parameters at their values for the base case of aqueous $30 \% \mathrm{wt}$.

$$
\operatorname{MEA}\left(\Delta \mathrm{p}_{\mathrm{A}}=100 \mathrm{~Pa}, \tau=0.05 \mathrm{~s}\right) \text {. }
$$

It is still unclear why our results differ from those of Hoff ${ }^{25}$. However, it must be pointed out that (i) the variation in $\mathrm{k}_{\mathrm{g}}$ * due to changes in $\mathrm{D}_{\mathrm{B}}$ is very small when compared to that caused by changing $H_{A}$ and $D_{A}$ and (ii) since $D_{B}$ will decrease with increasing viscosities, it will never decrease alone, but it is inexorably tied to shifts in $\mathrm{D}_{\mathrm{A}}$ as well. The net result of mounting viscosities will therefore always be decreasing mass transfer coefficients.

To summarize the results of the analyses carried in Section 3, it has been assessed that changes in $\mathrm{H}_{\mathrm{A}}$ and $\mathrm{D}_{\mathrm{A}}$ have by far the strongest impact on $\mathrm{k}_{\mathrm{g}}{ }^{*}$, enhancing it up to five times depending on the base case considered. The dielectric permittivity $\varepsilon$ has a moderate influence in mass transfer rates, particularly in CASE B. Comparatively, changes in $\mathrm{D}_{\mathrm{B}}, \mathrm{k}_{2}$ and $\mathrm{k}_{\mathrm{b}} / \mathrm{k}_{-1}$ have little effect on mass transfer rates.

\section{Section 4 - Explicit parametric analysis for thermal phenomena in the absorber}

This Section 4 will carry a parametric analysis on the temperature bulge and subsequent loss of $\mathrm{CO}_{2}$ capture capacity as a function of diluent properties. The base case is aqueous $30 \% \mathrm{wt}$. MEA as calculated with the parameters obtained in Section 1 and the mixing rules delineated in Section 2. For this analysis, the liquid-to-raw gas ratio in mass basis has been fixed at $\mathrm{L} / \mathrm{G}$ $=18.5 \mathrm{~kg}$ solvent $\cdot \mathrm{kg} \mathrm{CO}_{2}^{-1}$ while the lean solvent loading was set to $\alpha=0.20 \mathrm{~mol} \mathrm{CO}_{2} \cdot \mathrm{mol}$ $\mathrm{MEA}^{-1}$. The only parameters worth looking at in this analysis are the diluent heat capacity $\mathrm{C}_{\mathrm{P}}$, 
both in liquid and vapor phases, and its saturation pressure $p^{\text {sat }}$. Effects on $\mathrm{CO}_{2}$ capture capacity, maximum temperature at the temperature bulge and solvent volatilization have been investigated. We have decided to set the $\mathrm{CO}_{2}$ content in the raw gas at $\mathrm{Y}_{\mathrm{CO} 2}=10 \% \mathrm{v} / \mathrm{v}$, since it is around this $\mathrm{Y}_{\mathrm{CO} 2}$ that the main discrepancies in performances are observed for all solvents in Section 3.3 of the manuscript.

In Figure S4-1, one can see that the heat capacities of the diluent, both in liquid and vapor phase, have little effect on $\mathrm{CO}_{2}$ capture performances, maximum temperatures and diluent vaporization. Because of its relevance, we will only discuss the effect of liquid phase heat capacity. One important issue to be taken into account is that this liquid phase $C_{P}$ is responsible for the 'staying power' of the heat generated by the absorption of $\mathrm{CO}_{2}$. At very low heat capacities, this staying power is very low, meaning that the exothermic heat of $\mathrm{CO}_{2}$ absorption is quickly dissipated. This is why $\mathrm{T}_{\mathrm{MAX}}$ is relatively low and solvent volatilization is high for small liquid phase $C_{P}$. As $C_{P}$ increases, so does this staying power, meaning $T_{M A X}$ steadily increases and solvent volatilization decreases. Eventually one observes a plateau in the $\mathrm{T}_{\mathrm{MAX}}$ versus liquid phase $C_{P}$ plot, which accounts for the fact that the $C_{P}$ is high enough so that the temperature of the liquid stops depending too much on the exothermicity of the reaction between $\mathrm{CO}_{2}$ and amine. Meanwhile, the increase of $\mathrm{CO}_{2}$ capture is associated with less solvent volatilization: since our absorber is designed as an isobaric column, less solvent volatilization results in increased $\mathrm{CO}_{2}$ partial pressures. 

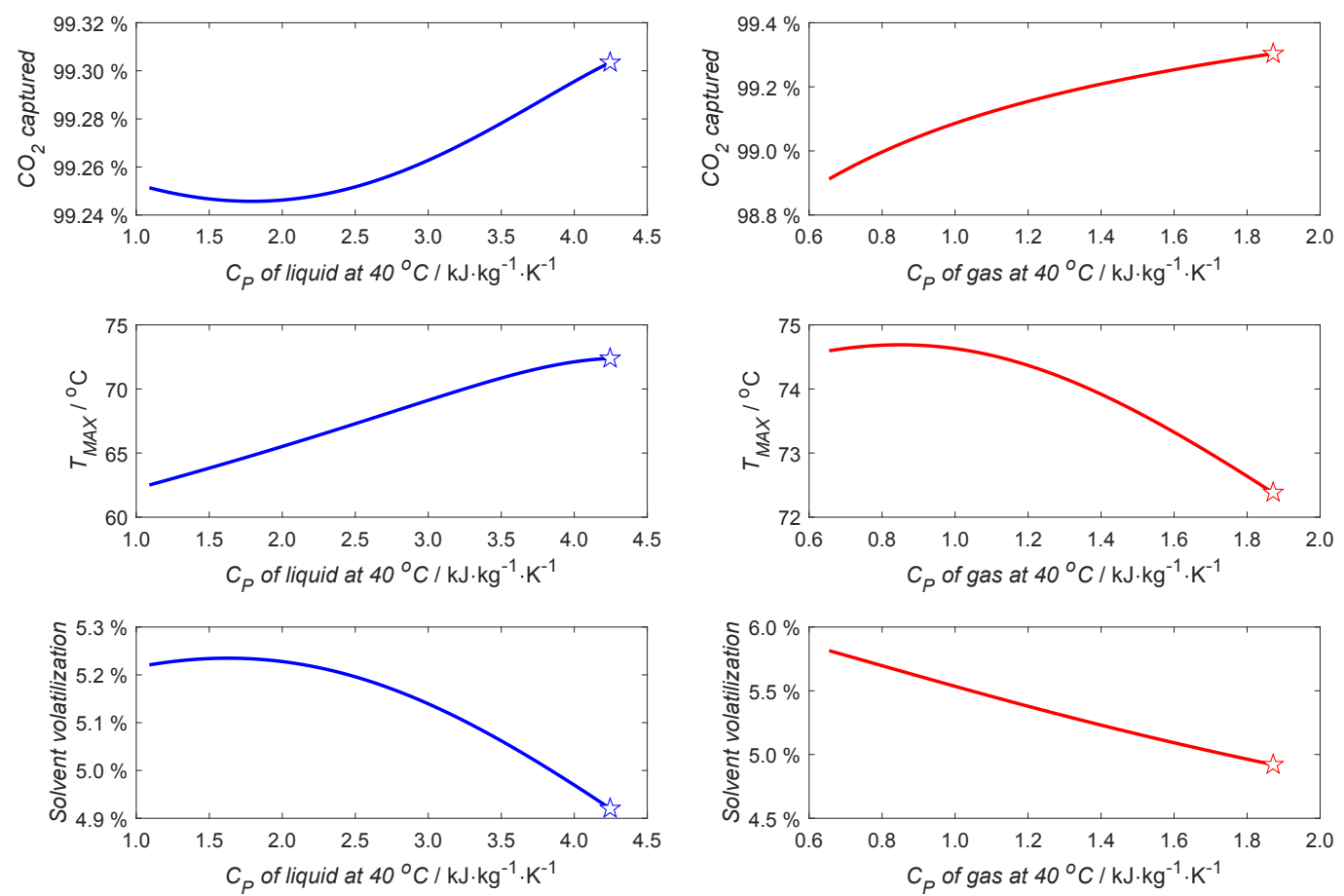

Figure S4-1. Analyses on the effect of liquid and gas heat capacities on thermal phenomena in the absorber employing solvents based on aqueous $30 \% \mathrm{wt}$. MEA (L/G $=18.5 \mathrm{~kg}$ solvent $\cdot \mathrm{kg} \mathrm{CO}_{2}{ }^{-1}$, lean loading $\alpha=0.20 \mathrm{~mol} \mathrm{CO} \cdot \mathrm{mol} \mathrm{MEA}^{-1}$, absorber with 5 theoretical stages, $\mathrm{Y}_{\mathrm{CO} 2}=10 \% \mathrm{v} / \mathrm{v}$ ). The stars represent values obtained for the base case with aqueous MEA.

Figure S4-2 shows that, with $\mathrm{Y}_{\mathrm{CO} 2}=10 \% \mathrm{v} / \mathrm{v}$, a decrease in the volatility of the diluent when compared to water brings a slight decrease in $\mathrm{CO}_{2}$ capture capacity together with a decrease in diluent volatilization. Clearly there are two opposing forces here: a lower $\mathrm{p}^{\text {sat }}$ means less solvent volatilization, which benefits $\mathrm{CO}_{2}$ absorption (more $\mathrm{CO}_{2}$ driving force in an isobaric column, as discussed previously) and therefore heat generation through the exothermic reaction, but also less cooling of the liquid phase. The inflection observed in the $T_{\text {MAX }}$ versus $p^{\text {sat }}$ curve is a result of these two opposing forces. The fact that less $\mathrm{CO}_{2}$ is capture for decreasing $\mathrm{p}^{\text {sat }}$ suggests that the lack of cooling overwhelms the higher driving forces in solvents with low volatility, resulting in a loss of $\mathrm{CO}_{2}$ capture capacity. Cooling effects also explain why, for high $\mathrm{p}^{\text {sat }}$ values, $\mathrm{T}_{\mathrm{MAX}}$ decreases and the amount of $\mathrm{CO}_{2}$ captured achieves its thermodynamical plateau. 

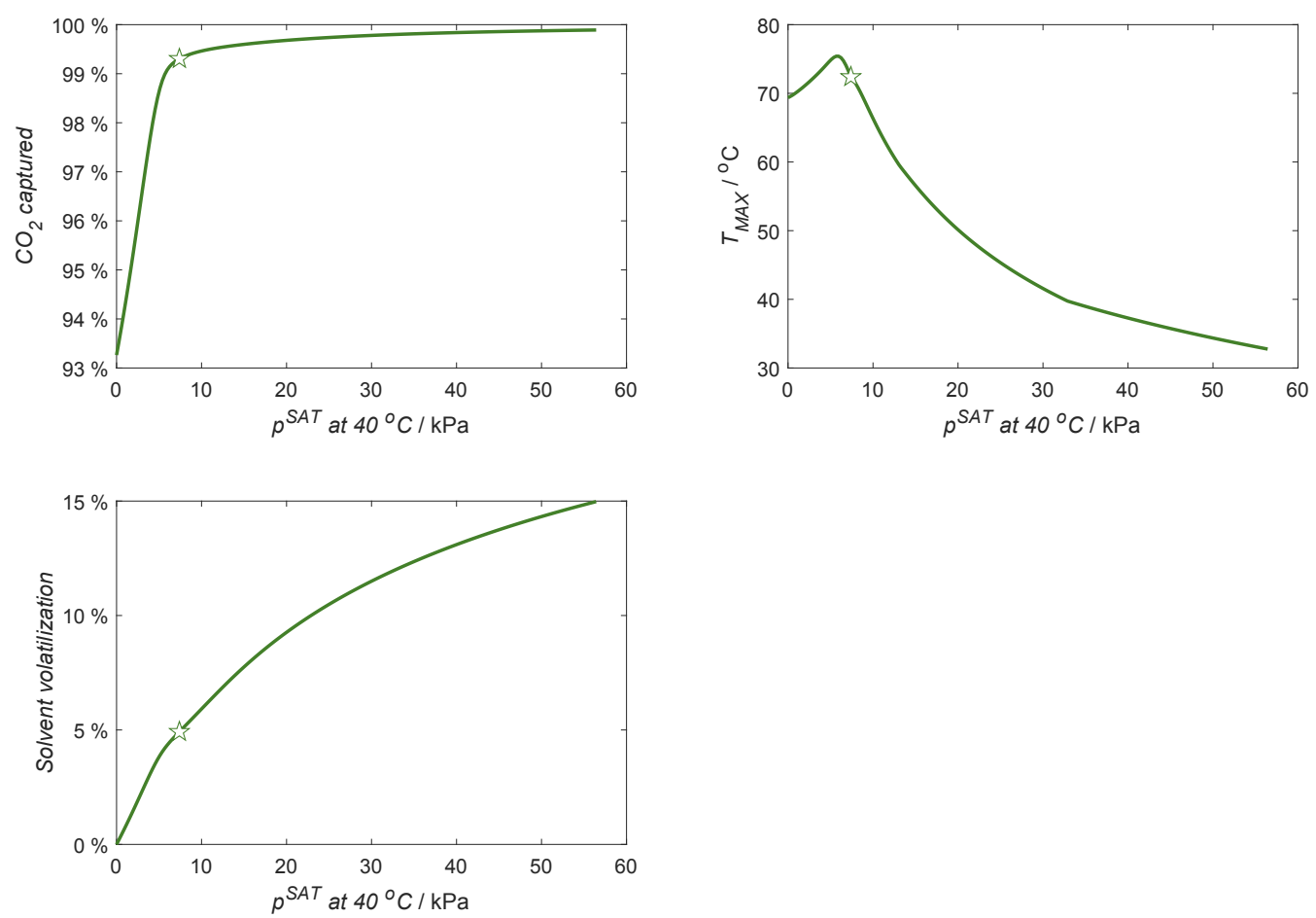

Figure S4-2. Analyses on the effect of solvent volatility on thermal phenomena in the absorber employing solvents based on aqueous $30 \% \mathrm{wt}$. MEA (L/G $=18.5 \mathrm{~kg}$ solvent $\cdot \mathrm{kg}$ $\mathrm{CO}_{2}{ }^{-1}$, lean loading $\alpha=0.20 \mathrm{~mol} \mathrm{CO}{ }_{2} \cdot \mathrm{mol} \mathrm{MEA}^{-1}$, absorber with 5 theoretical stages, $\mathrm{Y}_{\mathrm{CO} 2}=$

$10 \% \mathrm{v} / \mathrm{v})$. The stars represent values obtained for the base case with aqueous MEA.

When comparing Figure S4-1 and Figure S4-2, the effect of the diluent $\mathrm{p}^{\text {sat }}$ on $\mathrm{CO}_{2}$ capture capacity is clearly more relevant than that of $C_{P}$ in either of the phases. In fact, it is mostly volatilization, not the capacity for holding in internal energy, that enables more $\mathrm{CO}_{2}$ capture in face of rising temperatures. In hindsight, this makes sense. Though shifts in $C_{P}$ will affect the whole column roughly equally, shifts in $\mathrm{p}^{\text {sat }}$ will affect it unevenly - because the absorber already operates on a concentration differential basis - and will have more impact in either depressing or enhancing the capacity for $\mathrm{CO}_{2}$ absorption.

\section{Section 5 - Explicit parametric analysis for reboiler duties}

The present parametric analysis on the reboiler duties will be divided in the scenarios CASE C and CASE D. See discussion in Section 4.1 of the main manuscript for more information regarding these two different scenarios.

The base case in this discussion will be a solvent with $30 \%$ wt. MEA, and once again our first analysis relies on the parameters for aqueous MEA. However, water is a special diluent, having 
the largest $C_{P}$ and $\lambda$ of any compounds investigated in this study. Furthermore, as we have assumed in CASE $\mathrm{C}$ that the capital costs referring to the PHE are fixed and that this equipment is designed to obtain the best performance with aqueous $30 \%$ wt. MEA, it makes no sense to consider scenarios in which $\mathrm{T}_{\mathrm{X}}$ is higher than $105^{\circ} \mathrm{C}$. Taking Figure S5-1 for example, one can easily see how that is reflected in the plot for $\eta$. A solvent less viscous than water would provide a higher heat transfer coefficient $\mathrm{h}$ than aqueous $30 \% \mathrm{wt}$. MEA, but the maximum $\mathrm{T}_{\mathrm{X}}$ is fixed at $105{ }^{\circ} \mathrm{C}$, and no advantages are obtained in terms of reboiler heat duties. On the other hand, solvents more viscous than water will clearly deliver an increment in $Q_{R}$ in CASE C, as $T_{X}$ will be lower than $105{ }^{\circ} \mathrm{C}$. A similar discussion applies for $\mathrm{C}_{\mathrm{P}}$, so that there is an overlap between the curves obtained for CASE C and CASE D in the $C_{P}$ plot in Figure S5-1, since having a $C_{P}$ lower than that of water does not translate into higher values of $\mathrm{T}_{\mathrm{X}}$ in CASE C analysis.
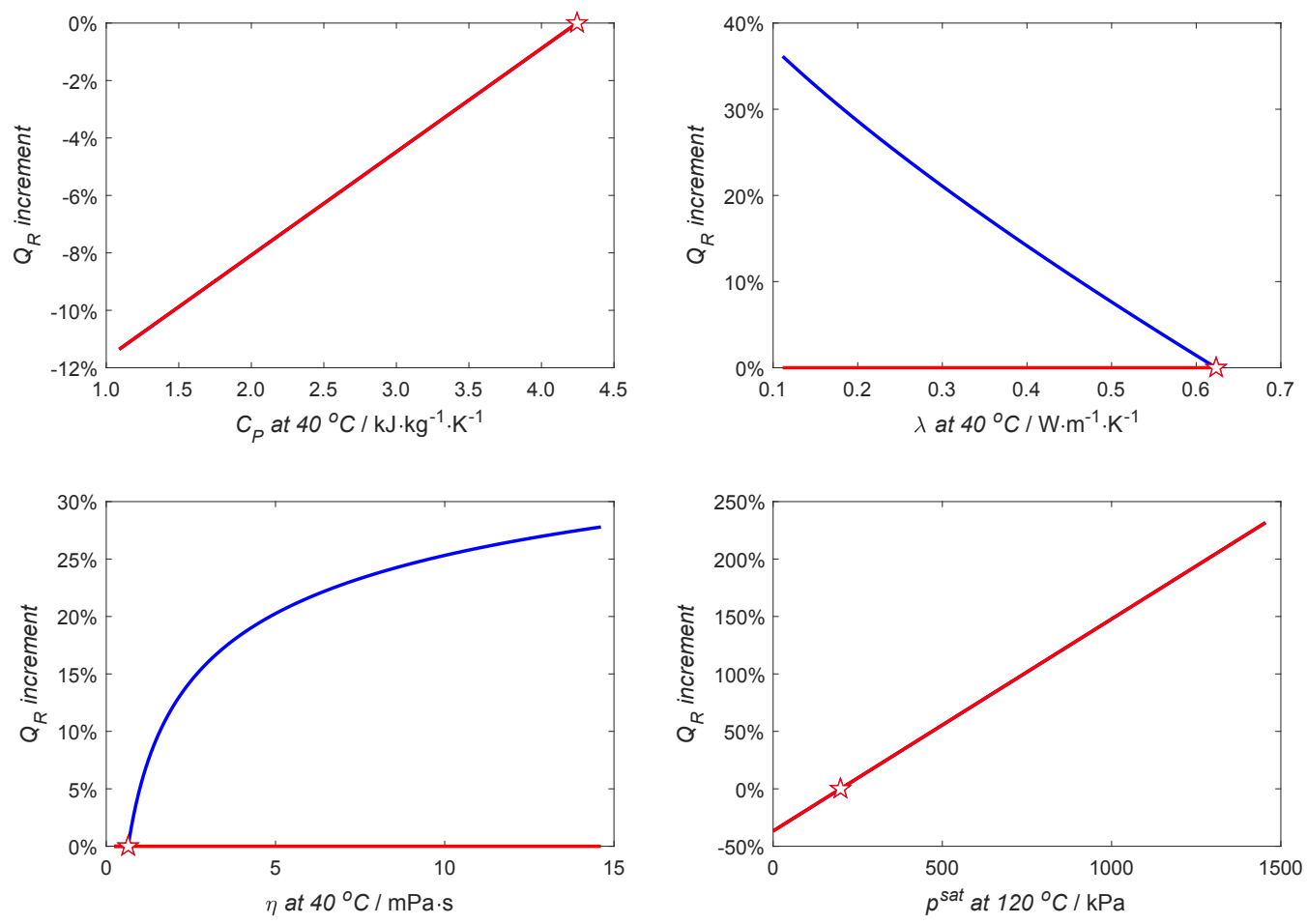

Figure S5-1. Analyses on the effect of different explicit parameters on the reboiler duty increments of solvents based on aqueous $30 \% \mathrm{wt}$. MEA $\left(\mathrm{T}_{\mathrm{X}}\right.$ varies in CASE $\mathrm{C}, \mathrm{T}_{\mathrm{X}}=105^{\circ} \mathrm{C}$ in CASE D, $\mathrm{T}_{\mathrm{R}}=120^{\circ} \mathrm{C}, \mathrm{p}_{\mathrm{A}}=10^{2} \mathrm{kPa}$ ); the blue lines refer to CASE C whereas the red lines refer to CASE D. The stars represent values obtained for the base case with aqueous MEA.

It is clearly more interesting to consider a different solvent than aqueous $30 \% \mathrm{wt}$. MEA for the base case analysis. As done previously, this base solvent will be NMP $+30 \%$ wt. MEA, and 
the results are shown in Figure S5-2. There it is easier to see the distinctions between CASE C and CASE D, and no irregularities such as the ones seen on Figure S5-1 are present.

While higher viscosities have the effect of increasing $Q_{R}$ required for solvent regeneration in CASE C, the opposite happens for $\lambda$ (see blue lines in Figure S5-1). In fact, $\mathrm{Q}_{\mathrm{R}}$ is highly coupled with $\lambda$ in CASE C, and one can observe an almost linear trend between these two variables. This naturally does not happen with CASE D, which shows $\mathrm{Q}_{\mathrm{R}}$ as being totally independent of both viscosity and thermal conductivity. Both in CASE C as in CASE D, the sensible heat of warming the solvent from 105 to $120^{\circ} \mathrm{C}$ and the latent heat of vaporization of the solvent make it so that $C_{P}$ and $\mathrm{p}^{\text {sat }}$ have a big influence in $Q_{R}$, with $\mathrm{p}^{\text {sat }}$ having the strongest among the two.
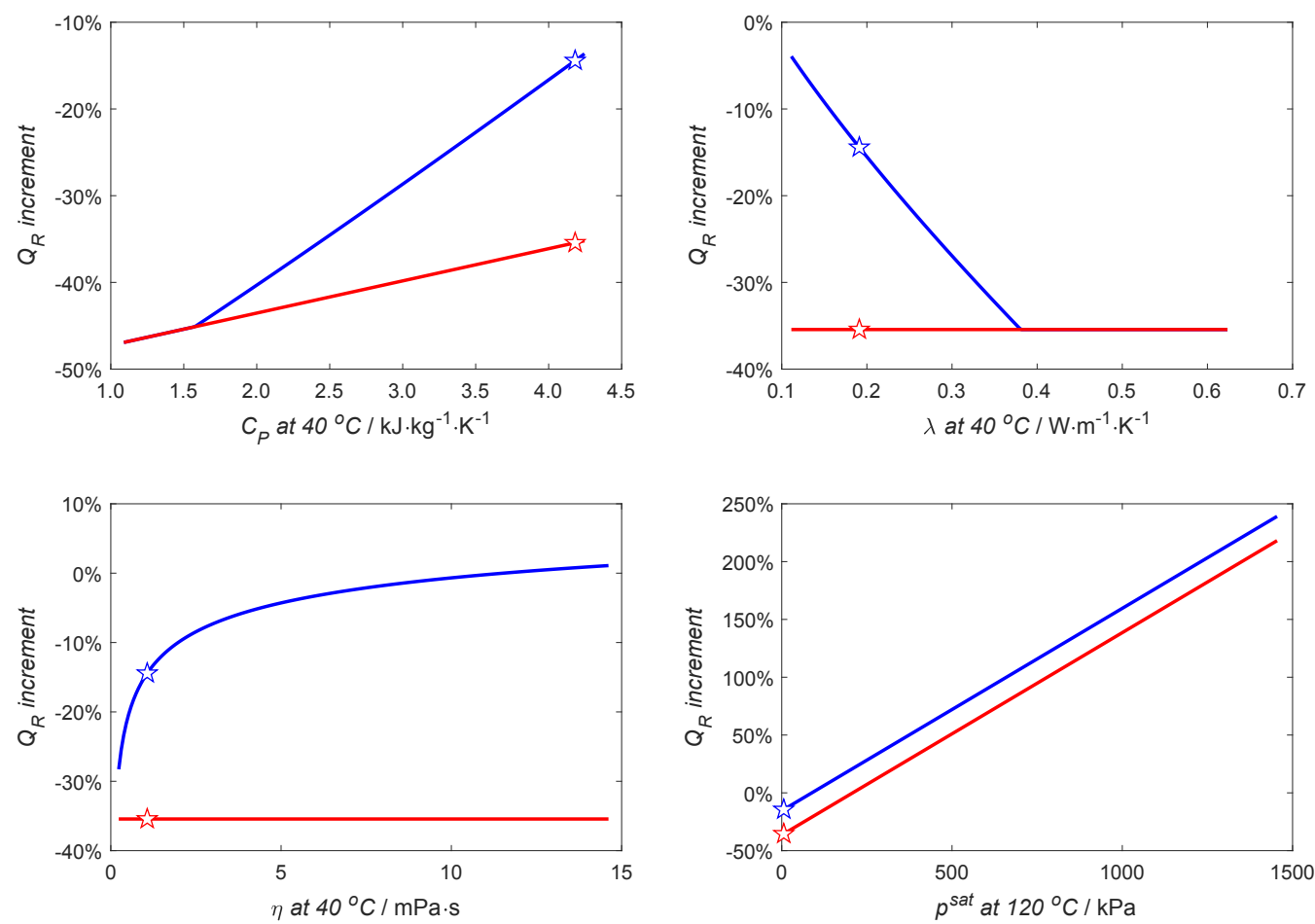

Figure S5-2. Analyses on the effect of different explicit parameters on the reboiler duty increments of solvents based on NMP $+30 \%$ wt. MEA $\left(\mathrm{T}_{\mathrm{X}}\right.$ varies in CASE C, $\mathrm{T}_{\mathrm{X}}=105^{\circ} \mathrm{C}$ in CASE D, $\mathrm{T}_{\mathrm{R}}=120^{\circ} \mathrm{C}, \mathrm{p}_{\mathrm{A}}=10^{2} \mathrm{kPa}$ ); the blue lines refer to CASE C whereas the red lines refer to CASE D. The stars represent values obtained for the base case with NMP + MEA.

These analyses highlight first and foremost the relevance of $\mathrm{p}^{\text {sat }}$ when investigating reboiler heat duties for water-lean solvents. Furthermore, the CASE C study shows the individual impacts of $C_{P}, \lambda$ and $\eta$, and one can conclude that their importance comes in the order $\eta>\lambda>$ $C_{P}$ by looking at the $Q_{R}$ increments both in Figure S5-1 and Figure S5-2. 
In conclusion, and just as already stated by Yuan and Rochelle ${ }^{26}$, the lower heat capacities typical of many organic diluents should not be evaluated in a vacuum when making a decision regarding water-lean solvents. As demonstrated, viscosity and thermal conductivity (both commonly higher in organic solvents than in water) play a significative role in reboiler duties, at least when the efficiency of the cross-heat exchanger is taken into account.

\section{Bibliography}

(1) Chernyak, Y.; Clements, J. H. Vapor Pressure and Liquid Heat Capacity of Alkylene Carbonates. 2004. https://doi.org/10.1021/je034173q.

(2) Yaws, C. L. Thermal Conductivity of Liquid - Inorganic Compounds. In Transport Properties of Chemicals and Hydrocarbons; William Andrew, 2009; pp 396-402. https://doi.org/10.1016/B978-0-8155-2039-9.50013-2.

(3) Hansen, C. M. Hansen Solubility Parameters: A User's Handbook; CRC Press, 2007.

(4) Rumble, J. R.; Lide, D. R.; Bruno, T. J. CRC Handbook of Chemistry and Physics: A Ready-Reference Book of Chemical and Physical Data; 2008.

(5) Yang, T.; Xia, S.; Song, S.; Fu, X.; Ma, P. Densities and Viscosities of NFormylmorpholine $(\mathrm{NFM})+\mathrm{p}$-Xylene, + o-Xylene, $+\mathrm{m}$-Xylene at Different Temperatures and Atmospheric Pressure. 2007. https://doi.org/10.1021/je7002513.

(6) Yaws, C. L.; Pike, R. W. Density of Liquid-Organic Compounds. In Thermophysical Properties of Chemicals and Hydrocarbons; Elsevier Inc., 2009; pp 106-197. https://doi.org/10.1016/B978-081551596-8.50008-0.

(7) Yaws, C. L.; Le Xuan Dang, L. Viscosity of Liquid - Organic Compounds. In Transport Properties of Chemicals and Hydrocarbons; William Andrew, 2009; pp 101-193. https://doi.org/10.1016/B978-0-8155-2039-9.50008-9.

(8) Yaws, C. L. Thermal Conductivity of Liquid - Organic Compounds. In Transport Properties of Chemicals and Hydrocarbons; William Andrew, 2009; pp 299-395. https://doi.org/10.1016/B978-0-8155-2039-9.50012-0.

(9) Yaws, C. L. The Yaws Handbook of Physical Properties for Hydrocarbons and Chemicals: Physical Properties for More Than 54,000 Organic and Inorganic Chemical Compounds, Coverage for C1 to C100 Organics and Ac to Zr Inorganics: Second Edition; Elsevier Inc., 2015. 
(10) Tuliszka, M.; Jaroszyk, F.; Portalski, M. Absolute Measurement of the Thermal Conductivity of Propylene Carbonate by the AC Transient Hot-Wire Technique; 1991; Vol. 12.

(11) Barthel, J.; Neueder, R.; Roch, H. Density, Relative Permittivity, and Viscosity of Propylene Carbonate + Dimethoxyethane Mixtures from $25{ }^{\circ} \mathrm{C}$ to $125{ }^{\circ} \mathrm{C} .2000$. https://doi.org/10.1021/je000098x.

(12) Moumouzias, G.; Ritzoulis, G. Viscosities and Densities for Propylene Carbonate + Toluene at 15, 20, 25, 30, and $35^{\circ} \mathrm{C} ; 1992 ;$ Vol. 37.

(13) Muhuri, P. K.; Hazra, D. K. Density and Viscosity for Propylene Carbonate + 1,2Dimethoxyethane at 298.15, 308.15, and $318.15 \mathrm{~K}$; 1994; Vol. 39.

(14) Jakli, G.; Alexander Van Hook, W. The Vapor Pressures of Dimethyl Sulfoxide and Hexadeuterodimethyl Sulfoxide from about 313 to 453 K. J. Chem. Thermodyn. 1972, 4 (6), 857-864. https://doi.org/10.1016/0021-9614(72)90007-9.

(15) Poling, B. E.; Prausnitz, J. M.; O’Connell, J. P. (John P. The Properties of Gases and Liquids; McGraw-Hill, 2001.

(16) Grunberg, L.; Nissan, A. H. Mixture Law for Viscosity. Nature. 1949, pp 799-800. https://doi.org/10.1038/164799b0.

(17) Skylogianni, E.; Wanderley, R. R.; Austad, S. S.; Knuutila, H. K. Density and Viscosity of the Nonaqueous and Aqueous Mixtures of Methyldiethanolamine and Monoethylene Glycol at Temperatures from 283.15 to 353.15 K. J. Chem. Eng. Data 2019, 64 (12), 5415-5431. https://doi.org/10.1021/acs.jced.9b00607.

(18) Wanderley, R. R.; Yuan, Y.; Rochelle, G. T.; Knuutila, H. K. CO2 Solubility and Mass Transfer in Water-Lean Solvents. Chem. Eng. Sci. 2019, 202, 403-416. https://doi.org/10.1016/J.CES.2019.03.052.

(19) Reynolds, J. A.; Hough, J. M. Formulae for Dielectric Constant of Mixtures. Proc. Phys. Soc. Sect. B 1957, 70 (8), 769-775. https://doi.org/10.1088/0370-1301/70/8/306.

(20) Shulgin, I.; Ruckenstein, E. Henry's Constant in Mixed Solvents from Binary Data. 2002. https://doi.org/10.1021/ie010911x.

(21) Sada, E.; Kumazawa, H.; Han, Z. Q.; Matsuyama, H. Chemical Kinetics of the Reaction 
of Carbon Dioxide with Ethanolamines in Nonaqueous Solvents. AIChE J. 1985, 31 (8), 1297-1303. https://doi.org/10.1002/aic.690310808.

(22) Snijder, E. D.; Te Riele, M. J. M.; Versteeg, G. F.; Van Swaaij, W. P. M. Diffusion Coefficients of Several Aqueous Alkanolamine Solutions. 1993, 38 (3), 475-480. https://doi.org/10.1021/je00011a037.

(23) Aronu, U. E.; Gondal, S.; Hessen, E. T.; Haug-Warberg, T.; Hartono, A.; Hoff, K. A.; Svendsen, H. F. Solubility of CO2 in 15, 30, 45 and 60 Mass\% MEA from 40 to $120{ }^{\circ} \mathrm{C}$ and Model Representation Using the Extended UNIQUAC Framework. Chem. Eng. Sci. 2011, 66 (24), 6393-6406.

(24) Aronu, U. E.; Lauritsen, K. G.; Grimstvedt, A.; Mejdell, T. Impact of Heat Stable Salts on Equilibrium CO2 Absorption. In Energy Procedia; Elsevier Ltd, 2014; Vol. 63, pp 1781-1794. https://doi.org/10.1016/j.egypro.2014.11.185.

(25) Hoff, K. A. Modeling and Experimental Study of Carbon Dioxide Absorption in a Membrane Contactor, Fakultet for naturvitenskap og teknologi, 2003.

(26) Yuan, Y.; Rochelle, G. T. Lost Work: A Comparison of Water-Lean Solvent to a Second Generation Aqueous Amine Process for CO 2 Capture. Int. J. Greenh. Gas Control 2019, 82-90. https://doi.org/10.1016/j.ijggc.2019.03.013. 